\title{
The Determinants of the Technical Efficiency of Secondary Schools in Malaysia: Panel Evidence
}

\author{
Rozita Baba ${ }^{1 *}$, Zulkefly Abdul Karim², Mariani Abdul-Majid ${ }^{3}$, \\ Noorasiah Sulaiman ${ }^{4}$ \\ 'University College of Islam Melaka, Malaysia \\ 2,3,4 National University of Malaysia, Malaysia \\ E-mail: 'rozita@kuim.edu.my, 2zak1972@ukm.edu.my, \\ 33mariani@ukm.edu.my, ${ }^{4}$ rasiahs@ukm.edu.my \\ ${ }^{*}$ Corresponding Author
}

\section{JEL Classification:}

$\mathrm{H} 5$

$\mathrm{H} 75$

Received: 02 September 2020

Revised: 02 November 2020

Accepted: 11 November 2020

\begin{abstract}
This study aims to identify the level of technical efficiency of secondary schools and its determinants using the data of 626 Malaysian secondary schools over 2010-2014. Two estimation techniques have been used; the first step is to estimate the school's efficiency score by employing a Data Envelopment Analysis approach. In the second step, we examine the factors affecting the schools' efficiency using a static panel data analysis. The main findings revealed that secondary education is technically inefficient, and on average, the schools can increase their output by $33 \%$ using the same resources. Secondary schools in rural areas and less-developed states indicate a better technical efficiency level than schools in urban areas and developed states. Factors that affect technical efficiency are school size, per capita income, and average wage. The findings suggest that the school may perform better by increasing the schools' size by having more classes. The opportunities to increase residents' and households' income may help the areas perform better than others.
\end{abstract}

\section{Keywords:}

technical efficiency, efficiency determinants, secondary school, data envelopment analysis, static panel data

\section{How to Cite:}

Baba, R., Karim, Z. A., Majid, M. A., \& Sulaiman, N. (2021). The Determinants of The Technical Efficiency of Secondary Schools in Malaysia: Panel Evidence. Etikonomi, 20(1), 169 - 184. https://doi.org/10.15408/etk.v20i1.17204. 


\section{Introduction}

The economic downturn and globalization have forced the government to spend most of its national income to enhance academic excellence and educational development to ensure human capital quality for the country's economic development. Education efficiency has become an important issue in public sector delivery, given the pressing government budget deficit in many countries. With government expenditure constraints, the assessment of efficiency in using these resources becomes very important and critical. Apart from that, efficient resource allocation is also essential to achieve academic excellence, economic growth, and supply of quality human resources (Psacharopoulos, 2004; 2018). From 2014 to 2018, investment in the education sector was RM 56,627 million (2014) and increased to RM 61,641 million (2018), in which the highest allocation of government service expenditure. Where secondary school expenses cover almost 30 percent of the total education expenses. The existing expenditure level will be maintained provided that efficiency and effectiveness studies are conducted (Malaysian Education Development Plan, 2013-2025).

The large number of secondary schools spending from public funds and the relatively low academic performance warrant further evaluation of the secondary school's efficiency. Malaysian secondary school is found technically inefficient in utilizing its educational resources to achieve better results than other countries (Arshad, 2013). Therefore, this study aims to estimate the level and determinants of the selected secondary schools' technical efficiency in four states in Malaysia, namely Selangor, Melaka, Kedah, and Terengganu. The data from 2010-2014 for every 626 schools have been used to achieve the objectives by employing two-stage analysis. We estimate the school's efficiency score by employing a Data Envelopment Analysis approach in the first stage. Then the static panel data analysis is used in estimating the determinants of schools technical efficiency.

The findings suggest that the secondary education is technically inefficient and the schools could have increased output by 33 percent given the same resources. Secondary schools in rural areas and less-developed state indicate a better level of technical efficiency than schools in urban areas and developed states. Factors that significantly affect technical efficiency are school size, per capita income and wage. The findings suggest that the school may perform better with the increase in the size of the schools by having more classes. Efficiency is the effectiveness of using inputs to produce outputs. The optimum efficiency can be generated and influenced by efficient input factors such as the quality or workers. Where, technical efficiency illustrates the ability of firms to produce maximum output when given a set of inputs (Farrell 1957). An efficiency score of one value indicates technical efficiency, and a score of less than one indicates technical inefficiency (Porcelli 2009).

Studies on technical efficiency have been carried out at various fields or organizations of study based on objective, context, and input and output selection. Most researchers use different techniques to estimate production boundaries, productivity, and technical efficiency. Two approaches, namely, Data Envelopment Analysis (DEA) and Stochastic 
Frontier Analysis (SFA), have dominated education efficiency. Data Envelopment Analysis (DEA) are widely applied at all levels of the education sector (Podinovski et al., 2014; Johnson \& Ruggiero, 2014; Huguenin, 2015; Atici \& Podinovski, 2015; Haelermans \& Ruggiero, 2017; Goncharuk, 2018). The second method is the Stochastic Frontier Analysis (SFA) (Scippacercola \& Ambra, 2014; Muvawala, \& Hisali, 2012). Both approaches are often used to assess technical efficiency levels by either using cross-section data or panel data. Based on previous studies, many studies measure technical efficiency, especially in education that is closely related to primary school, secondary school, and tertiary education.

Extensive research on the technical efficiency of the education sector has been conducted worldwide. Calero et al. (2020) found that the evolution of age cohorts' efficiency levels shows that higher education is more efficient for younger cohorts, while lower and upper secondary education presents a stable trend. Meanwhile, Johnes \& Virmani (2020) evaluate the efficiency of education systems in four low and middleincome countries. The findings revealed that no country does the educational system perform uniformly badly or well. Other than that, Buerger \& Bifulco (2019) found that charter schools increase the cost of providing education and that these cost increases are larger than short-run efficiency gains but are offset by efficiency gains in the long term. Agasisti et al. (2014) find that almost 96.5\% of schools are inefficient, and on average, Tunisian schools could have increased their results by $27 \%$ using the same resources. Nahar \& Arshad (2014) found that almost all of the 16 selected OIC members are technically inefficient in utilizing their educational resources to achieve better Trends in International Mathematics and Science Study (TIMSS) results compared to the non-OIC countries. Even after controlling for environmental factors, secondary education in the OIC countries remains technically inefficient. Studies on secondary school efficiency use various variables as output, such as numbers of the pupil, numbers of graduates, passing rates, and average test scores. Often the choices are driven by data availability. However, none of these are ideal. The number of pupils may capture the quantity of scholarly output but does not capture the quality. The output that is always used is the test score (Podinovski et al., 2014; Agasisti et al., 2014; Liang, 2014).

The contribution of the paper is in two folds. First, the paper employs secondary schools' national examination results as the output of education performance. This reflects the actual achievement of a secondary school student in Malaysia. Unlike in previous studies that employ international examination results such as a study by Nahar \& Arshad (2014) and Arshad (2013) that uses Trends in International Mathematics and Science Study (TIMSS). In contrast, Agasisti et al. (2014) use Programme for International Student Assessment (PISA) as an ouput. The use of Sijil Pelajaran Malaysia result arguably is more reflective of the secondary school academic achievement in Malaysia. Previous studies by Nahar \& Arshad (2014) and Arshad (2013) only discussed about the school efficiency. This study is different because this study examines the determinants of technical efficiency as well as the level of technical efficiency of secondary schools in Malaysia. 
The inputs are most often used in the study of technical efficiency, namely government spending and the student-teacher ratio. Akbar (2018) found that the greatest impact inputs have on the cost per teacher and cost per student. Drebee \& Razak (2018) conclude that colleges that have not achieved the required efficiency examine the factors that have contributed to this outcome to acquire knowledge of weaknesses and imbalances in their inputs and outputs could exploit the available resources efficiently by comparing their inputs and outputs with those of peer colleges. Meanwhile, the China government has increased its spending on the education sector and other learning inputs. However, if schools are operating at low efficiency, educational resources will not be fully utilized, and the success of primary education in China will not be determined (Danu \& Zuhdi 2013). Badri et al. (2014) find that per capita spending on the health and education sector was efficient in some countries for the 2006-2010-study year. A study in Indonesia used the ratio of teachers and students. The average expenditure as input and output used was the average student achievement score in 33 regions in Indonesia, with an average technical efficiency of 86\% (Agasisti \& Zoido 2015). Besides the student-teacher ratio, the average socioeconomic status of students in the school, number of computers per student, the average score in mathematics, and test scores in reading also used (Hussain et al., 2015). The public schools in Pakistan are technically inefficient under CRS and VRS while efficient on technical efficiency, pure efficiency, and scale efficiency.

Based on previous research on school efficiency determinants, the factors that often influence the efficiency are socio-economic factors such as parental income, parental education, schoolmates, and schoolmates' family background. Hussain et al. (2015) and Agasisti \& Sibiano (2014) find that students' socio-economic status and parental education significantly affect school efficiency, especially in rural areas. Besides socioeconomic factors, school size factors are also often used. Agasisti (2014) found that per capita GDP has a negative relationship with efficiency. School size factors have different effects on efficiency. Some researchers support the large size of schools increased school efficiency (Yahia \& Essid, 2019; Nauzeer et al., 2018), while others support the small size of schools (Burney et al., 2013). Previous studies suggest that the determinants of the efficiency of the secondary schools are parental income, parental education, schoolmates and family background of schoolmates.

\section{Methods}

A two-stage analysis involves data envelopment analysis (DEA) and static panel data approach is an appropriate approach to analyze this study. The first stage consists of the measurement of secondary school technical efficiency scores. In the second stage, static panel data analysis was performed with efficiency scores obtained from the first stage as dependent variables, while determinant factors are considered as independent variables. The study involved 626 secondary schools from four selected states (Selangor, Malacca, Kedah, and Terengganu). The data are studied by urban and rural schools and 
developed and less developed states. There were 398 (63.6\%) urban schools and 228 (36.4\%) rural schools. Of the state economy categories, there were 324 (51.8\%) schools in the developed states and $302(48.2 \%)$ schools in the less developed states. The study involved several secondary schools such as boarding schools, national secondary schools, religious, national secondary schools, and technical and vocational schools made up of 17-year-old students. Malaysia has multi-ethnic students consists of Malay, Chinese and Indian.

Studies using Data Envelopment Analysis (DEA) involve one output (average student grade) and two inputs (student-teacher ratio and operating expenses per student). Meanwhile, static panel data used one dependent variable and three independent variables. The dependent variable in this study was the school efficiency score. Meanwhile, the independent variable acts as the explanatory variable to examine its relationship to the dependent variable (school efficiency), namely school size, average wage, and per capita income.

\section{Data Envelopment Analysis (DEA)}

At the first stage, Data Envelopment Analysis (DEA) is employed to estimate each school's efficiency score. DEA, established by Farrell (1957), is a non-parametric linear programming technique that evaluates a set of comparable entities' relative efficiency by some specific mathematical programming models. These entities are often called decision-making units (DMUs). The selection of a set of weights that combines multiple outputs and multiple inputs is at the forefront of DEA analysis. DEAs can be performed by linear programming techniques where each DMU attempts to maximize the efficiency ratio (output to input) by selecting the best set of weights. DEA linear programming quality means that the maximum value of the objective function in the form of multiplier can also be expressed as the minimum value of the objective function.

The convex shape, according to Coelli et al. (2005), that the data distance in the envelope was much narrower than that of the concave CRS and that the technical efficiency score was greater or equal to that obtained in the CRS model. The gradient constraints also ensure each DMU is simply benchmarked or compared to a DMU of the same scale. If the DMUj is technically efficient ( $\theta j$ is equal to one), the " $\lambda \mathrm{j}$ " weight is one while the $\lambda$ weight for the other DMU is empty. In cases where DMUj is inefficient, the $\lambda$ weighting of any (or part) of the other DMUs must be positiveDMUs with high $\lambda$ show a high position as an example of DMUj.

Input and output targets can be used by DMUj to improve efficiency. With the knowledge of how to calculate CRS and VRS techniques' efficiency, the calculation of scale efficiency can be described. The range of technical efficiency (TE) is 0 to 1 . TE $=1$ implies that the firm is producing on its production frontier and is said to be technically efficient. 


\section{Model Specification}

In the second stage, we used a panel data estimation to examine the relationship between efficiency score and independent variables. The benefits of using static panel data include a much larger data set with more variability and less colinearity among the variables than is typical of cross-sectional or time-series data. Panel data sets can also identify and estimate the effects that are simply not detectable in cross-sections or pure time-series data. In this study, the selected independent variables used in analyzing factors influencing secondary school efficiency were school size, per capita income, and average wage. School size is the number of students in a school, per capita income is individual income in a year, and the average wage is average monthly wages in a year. The efficiency value represents the dependent variable. The static panel data for the empirical model of this study is as below:

$$
\text { Effi }_{\text {it }}=\alpha_{0}+\alpha_{1} \operatorname{lnSize}_{\text {it }}+{ }_{\alpha 2} \operatorname{lnwage}_{i t}+\alpha_{3} \operatorname{lnpercap}_{\mathrm{it}}+\mathrm{u}_{\mathrm{it}}
$$

Where, $\mathrm{u}_{\mathrm{i}, \mathrm{t}}=\lambda_{\mathrm{i}}+\mathrm{e}_{\mathrm{it}}$

Equation above can be written in the form of a fixed-effects model as follows:

$$
\text { Effi }_{i t}=\left(\lambda_{i}+\alpha_{0}\right)+\alpha_{1} \operatorname{lnSize}_{i t}+\alpha_{2} \text { lnwage }_{i t}+\alpha_{3} \operatorname{lnpercap}_{i t}+e_{i, t}
$$

It can also be written in the form of a random-effects model as follows:

$$
\text { Effi }_{\mathrm{it}}=\alpha_{0}+\alpha_{1} \operatorname{lnSize}_{\mathrm{it}}+\alpha_{2} \operatorname{lnwage}_{\mathrm{it}}+\alpha_{3} \operatorname{lnpercap}_{\mathrm{it}}+\lambda_{\mathrm{i}}+\mathrm{e}_{\mathrm{i}, \mathrm{t}}
$$

Where $\mathrm{Eff}_{\mathrm{it}}$ represents the school's efficiency measure and $\alpha_{0}$ is intercept. Size is the $\log$ for the school size. Wage is the log for an average wage. Percap is the log for per capita income representing community background, " $\lambda_{i}$ " is the school-specific effect, $e_{i t}$ is the remaining error term where $e_{i}\left(0, \sigma_{e i}\right)$, i represents the number of schools $i$ $(\mathrm{i}=1, \ldots, \mathrm{N})$, and $\mathrm{t}$ represents the time period $(\mathrm{t}=1, \ldots, \mathrm{T})$. The $\lambda_{\mathrm{i}}$ variable represents all the unobservable variables that are constant over time but vary by school. The $\alpha_{i}$ variable will be indicated by the coefficient of the shortcut variable for each school. The $\alpha_{\mathrm{i}}$ variable is assumed to be correlated with one or more of the independent variables found in the model. $U_{\text {it }}$ is called idiosyncratic error or random that changes over time. This is because it represents unobservable variables that change over time and affect dependent variables.

\section{Outliers Statistic}

DFITS statistical measurements have been used to detect data outliers. The DFITS measurement is a different scale between 'within the sample' and 'beyond the sample' to the observation's expected value. DFITS evaluates appropriate decisions for the model of 'including' and 'excluding' observations. DFITS statistics are calculated as follows:

DFITS $_{j}=r_{j} \sqrt{h_{j} / 1-h_{j}}$, where $r_{j}$ is a studentized (standardized) residual, $r_{j} \frac{e j}{s(j) \sqrt{1}-h j}$, with $s_{j}$ referring to root mean squared error of the regression equation with the $j_{j}$ observation removed. Working through the algebra shows that either a large value of leverage $\left(h_{j}\right)$ or a large absolute residual $\left(e_{j}\right)$ will generate a large IDFITSjl. The DFITS value measure is a scaled difference between the in-sample and put-of-sample predicted values for $\mathrm{jth}$ 
observation. DFITS evaluates the result of fitting the regression model, including and excluding that observation. Initially, 626 schools were listed from four states, which consisted of two categories: the developed and the less developed states. However, after considering incomplete school data and information, outliers' tracking test, the number of schools used for estimating is only 609.

\section{Hausman Test}

This test has been used in static panel data models in choosing the appropriate model, either fixed effect or random effects (Hausman 1978). Thus, the model of secondary school efficiency estimated using fixed and random effects. The differences between the two models are the fixed effect assumes that the school-specific effect is correlated with independent variables. Meanwhile, random effects assume that school-specific effects do not correlate with independent variables and allow time-invariant variables to play a role as explanatory variables in the model. According to Baltagi (2008), the derivative of the error for the estimator of the fixed effects model is $u_{i t}=\lambda_{i}+e_{i t}$, where $\lambda_{i}$ represent unobserved individual-specific effect, $\mathrm{e}_{\mathrm{it}}=0$ represents the assumed individual effect. Instead, in the random-effects model, it is stochastic and distributed, and the individual effect is not correlated with the error terms but is correlated with the regressors. The panel data model is a one-way error components model that allows for heteroskedasticity in individual specifications and designations using unbalanced panels. Based on the oneway model, the special effect assumes that $e_{i t}$ is constant in the fixed-effects model. In contrast, in random-effects models, $\mathrm{e}_{\mathrm{it}}$ is independent of the probability distribution.

All the independent variables are expected to have different effects on secondary school efficiency. The relationship between school sizes is negative $(\beta 1<0)$, which means increasing school size will reduce school efficiency. The relationship between average annual wage and per capita income is expected to be positive $(\beta 2>0)$, where increasing annual average wages and per capita income help improve school efficiency. Specifically, in a one-way model, the Hausman test hypothesis can be written as follows:

$$
\begin{aligned}
& \mathrm{H}_{0}: \mathrm{E}\left(\mathrm{v}_{\mathrm{it}} / \mathrm{x}_{\mathrm{it}}\right)=0 \\
& \mathrm{H}_{1}: \mathrm{E}\left(\mathrm{v}_{\mathrm{it}} / \mathrm{x}_{\mathrm{it}}\right) \neq 0
\end{aligned}
$$

The null hypothesis above indicates that if the individual effects are not correlated with the independent variables, then the random-effects model is chosen because it is efficient. On the other hand, if there is a correlation, then the fixed effect is consistent with the estimated coefficient. The random-effects model is not consistently used in the test results. Based on the estimates, the Hausman test value is 0.000 , which is less than 0.05; then, the fixed effects model is better used for analysis purposes.

\section{Result and Discussion}

In the first stage analysis, this study aims to measure the school's technical efficiency regarding the average student score using non-parametric of the DEA method. There are two inputs have been used, namely, student-teacher ratio and per-pupil 
expense (in term of Ringgit Malaysia). At the same time, the output is the average student score, which reflects school educational attainment. The second stage of analysis identifies factors that might significantly affect school efficiency. This study applies static panel data analysis. In this analysis, the dependent variable is the school efficiency, while the independent variables are school size, average wage, and per capita income (Ringgit Malaysia).

Table 1. Descriptive Statistics of The Variable

\begin{tabular}{lccccc}
\hline & Obs & Mean & Std. Deviation & Min & Max \\
\hline $\begin{array}{l}\text { Output } \\
\text { Efficiency }\end{array}$ & 2950 & 0.729 & 0.143 & 0.168 & 1 \\
Input & & & & \\
Per capita income & 2950 & 10.18 & 0.354 & 9.55 & 10.61 \\
School size & 2950 & 6.937 & 0.5713 & 4.836 & 8.39 \\
Average wages & 2950 & 7.571 & 0.1923 & 7.275 & 7.87 \\
\hline
\end{tabular}

Table 1 shows a descriptive analysis of the quantitative determinant variables used in this study. The table shows that the overall average output is 0.729 with a minimum output value of 0.168 ; the maximum output value is 1 . There are three inputs used; the first input was per capita income that average value of 10.18 , a minimum value of 9.55, and a maximum value of 10.61. The second inputs used were the school size with an average of 6.937, a minimum value of 4.836, and a maximum value of 8.39. Finally, the third inputs used were average monthly wages with an average of 7.571 , a minimum value of 7.275 , and a maximum value of 7.87 .

Table 2. Secondary School Efficiency Level

\begin{tabular}{cccccc}
\hline Level & $\mathbf{2 0 1 0}$ & $\mathbf{2 0 1 1}$ & $\mathbf{2 0 1 2}$ & $\mathbf{2 0 1 3}$ & $\mathbf{2 0 1 4}$ \\
\hline 1 & 4 & 8 & 6 & 7 & 12 \\
& $(0.64 \%)$ & $(1.28 \%)$ & $(0.96 \%)$ & $(1.12 \%)$ & $(1.92 \%)$ \\
$0.8-0.99$ & 49 & 22 & 161 & 180 & 222 \\
& $(7.82 \%)$ & $(3.51 \%)$ & $(25.72 \%)$ & $(28.75 \%)$ & $(35.5 \%)$ \\
$0.5-0.79$ & 374 & 465 & 379 & 357 & 319 \\
& $(59.74 \%)$ & $(74.28 \%)$ & $(60.5 \%)$ & $(57.03 \%)$ & $(50.96 \%)$ \\
$\leq 0.49$ & 199 & 131 & 80 & 82 & 73 \\
& $(31.79 \%)$ & $(20.93 \%)$ & $(12.78 \%)$ & $(13.10 \%)$ & $(11.66 \%)$ \\
Total & 626 & 626 & 626 & 626 & 626 \\
\hline
\end{tabular}

Note: Low $\leq 0.49$, medium (0.5-0.79), high (0.8-0.99) and efficient (1.00)

Table 2 displays the technical efficiency scores of four selected states in Malaysia for the period 2010 to 2014. The findings reveal that the efficiency value is rearranged based on the efficient, high, medium, and low level. The efficiency of the low level was on a scale of $\leq 0.49$, medium (0.5-0.79), high (0.8-0.99), and efficient (1.00). This five-year study shows that only four schools in 2010 were efficient and increased 
to 8 schools in 2011, declining to 6 secondary schools in 2012 and 12 secondary schools in 2014. The high-efficiency level was showing an increase from year to year except in 2011. The moderate level shows a decline in the number of schools except for 2011. The lower efficiency category shows a decline over the years as these secondary schools show improved levels of efficiency as of 2014; only 73 schools were in the lower level. As of 2014, 98\% of secondary schools in Malaysia are inefficient. These findings align with the results by Nahar \& Arshad (2014) and Podinovski et al. (2014).

Table 3. Urban and Rural Secondary School Efficiency Level

\begin{tabular}{|c|c|c|c|c|c|c|c|c|c|c|}
\hline \multirow{2}{*}{$\begin{array}{c}\text { Year/ } \\
\text { efficiency }\end{array}$} & \multicolumn{2}{|c|}{2010} & \multicolumn{2}{|c|}{2011} & \multicolumn{2}{|c|}{2012} & \multicolumn{2}{|c|}{2013} & \multicolumn{2}{|c|}{2014} \\
\hline & Urban & Rural & Urban & Rural & Urban & Rural & Urban & Rural & Urban & Rural \\
\hline 1 & 2 & 2 & 1 & 7 & 1 & 5 & 0 & 7 & 6 & 6 \\
\hline $0.8-0.99$ & 20 & 29 & 10 & 12 & 78 & 83 & 83 & 97 & 105 & 117 \\
\hline $0.5-0.79$ & 295 & 176 & 281 & 184 & 260 & 119 & 252 & 105 & 234 & 85 \\
\hline$\leq 0.49$ & 81 & 21 & 106 & 25 & 59 & 21 & 63 & 19 & 53 & 20 \\
\hline Maximum & 1 & 1 & 1 & 1 & 1 & 1 & 0.962 & 1 & 1 & 1 \\
\hline Minimum & 0.14 & 0.21 & 0.12 & 0.20 & 0.14 & 0.20 & 0.16 & 0.20 & 0.21 & 0.23 \\
\hline Average & 0.61 & 0.69 & 0.57 & 0.65 & 0.67 & 0.74 & 0.67 & 0.75 & 0.69 & 0.77 \\
\hline Sub total & 398 & 228 & 398 & 228 & 398 & 228 & 398 & 228 & 398 & 228 \\
\hline Total & \multicolumn{2}{|c|}{626} & \multicolumn{2}{|c|}{626} & \multicolumn{2}{|c|}{626} & \multicolumn{2}{|c|}{626} & \multicolumn{2}{|c|}{626} \\
\hline
\end{tabular}

Table 3 shows there are 398 schools in the urban area and 228 schools in a rural area. The high-efficiency levels show there were 20 schools (2010), up to 105 schools (2014) in the urban areas. Similarly, rural schools increased from 29 schools (2010) to 117 schools (2014). These findings show that academic achievement is improving. Low-level efficiency $(\leq 0.49)$ showed a declining number in both locations, with only 53 urban secondary schools and 20 rural high schools in 2014. School performance improved when the percentage of schools in the lower ranks decreasing. In terms of minimum efficiency, it was found that urban schools had a lower efficiency than rural schools, especially for 2011, at 11.8 percent compared to 19.5 percent for rural schools in 2013. This finding indicates that although both locations are inefficient, rural schools are more efficient than urban schools. This result is in line with the study by Johnes \& Virmani (2020), who found that rural schools often showed higher efficiency levels. Muvawala and Hisali (2012) also found urban schools to be technically inefficient than government-aided and rural schools. Conversely, Kantabutra (2009) find urban schools were also more efficient. Rural schools generally benefited from their closer ties with the local community. Denaux (2007) also find that urban schools are more efficient. 
Rozita Baba. The Determinants of the Technical Efficiency

Table 4. Secondary Schools Technical Efficiency of Advanced and Less Advanced States in Malaysia

\begin{tabular}{|c|c|c|c|c|c|c|c|c|c|c|}
\hline \multirow[t]{2}{*}{ Year } & \multicolumn{2}{|c|}{2010} & \multicolumn{2}{|c|}{2011} & \multicolumn{2}{|c|}{2012} & \multicolumn{2}{|c|}{2013} & \multicolumn{2}{|c|}{2014} \\
\hline & DS & LDS & DS & LDS & DS & LDS & DS & LDS & DS & LDS \\
\hline 1 & 0 & 4 & 4 & 4 & 3 & 3 & 4 & 3 & 5 & 7 \\
\hline 0.8-0.99 & 16 & 33 & 6 & 16 & 64 & 97 & 73 & 107 & 93 & 129 \\
\hline $0.5-0.79$ & 250 & 221 & 233 & 232 & 217 & 162 & 208 & 149 & 191 & 128 \\
\hline$\leq 0.49$ & 58 & 44 & 81 & 50 & 40 & 40 & 39 & 43 & 35 & 38 \\
\hline Maximum & 0.91 & 1 & 1 & 1 & 1 & 1 & 0.962 & 1 & 1 & 1 \\
\hline Minimum & 0.141 & 0.221 & 0.118 & 0.198 & 0.140 & 0.203 & 0.164 & 0.158 & 0.205 & 0.225 \\
\hline Average & 0.620 & 0.667 & 0.572 & 0.619 & 0.676 & 0.669 & 0.687 & 0.716 & 0.705 & 0.737 \\
\hline Sub total & 324 & 302 & 324 & 302 & 324 & 302 & 324 & 302 & 324 & 302 \\
\hline Total & \multicolumn{2}{|c|}{626} & \multicolumn{2}{|c|}{626} & \multicolumn{2}{|c|}{626} & \multicolumn{2}{|c|}{626} & \multicolumn{2}{|c|}{626} \\
\hline
\end{tabular}

${ }^{*}$ Note: $\mathrm{D}=$ Developed States, LD = Less Developed States

Table 4 shows the technical efficiency of secondary schools according to the developed and the less developed states' economic status. There are 324 schools in the developed states and 302 schools in the less developed states. Although located in less developed states, secondary school achievement in these states is relatively good. For example, in 2010, there is no efficient school in developed states than four schools in less developed states. In 2014, the less developed states showed better performance with seven schools than the five in developed states. Average efficiency by economic status indicates that schools in developed states have lower average efficiency than less developed states' efficiency. For example, in 2014, at 70.5\% in developed states compared to $73.7 \%$ in less developed states. The overall result shows that 289 schools in developed and 264 schools in less developed states achieved an efficiency level of more than 0.50 .

Table 5. Estimation Results of Static Panel Data for School Efficiency Determinants

\begin{tabular}{lcc}
\hline & Fixed effect & Random effect \\
\hline LnSize & -0.0762 & -0.025 \\
& $(-2.80)^{* * *}$ & $(-2.98)^{* * *}$ \\
LnWage & -0.191 & 0.0578 \\
& $(-0.59)$ & $(2.12)$ \\
LnPercap & 0.1317 & -0.0455 \\
& $(3.91)^{* * *}$ & $(-2.35)^{* *}$ \\
No. of observation & 2950 & 2950 \\
No. of groups & 609 & 609 \\
R-square & 0.0072 & 0.0187 \\
Prob $>$ F / & & \\
Prob $>$ chi2 & 0.0000 & 0.000 \\
\hline
\end{tabular}

Note: The figure in parentheses is t value. ${ }^{* * *}$ Significant at level $1 \%$; ${ }^{* *}$ Significant at level $5 \%,{ }^{*}$ Significant at level $10 \%$. 
Table 5 illustrates the results of static panel data estimation. Based on the estimation, the Hausman test value is 0.000 , so the fixed effects model is more suitable for analysis purposes. Therefore, the discussion of the study results focused on the fixed effects model only while the random effects model estimates were reported for reference. The result of the analysis shows that only two independent variables are statistically significant at a $1 \%$ significant level in influencing the secondary school efficiency. School size variables were negatively affects the school efficiency, in which an increase of $1 \%$ in school size leads to reduce the school efficiency by 0.076 units. These findings align with Tsakiridou \& Stergiou (2013), who found a negative relationship between school size and efficiency in Greece's study. However, the results are inconsistent with some previous studies; for example, research by Yahia \& Essid (2019), and Huguenin (2015), who found that large school size would improve school efficiency. In contrast, Agasisti (2014) found that there is no relationship between school size and efficiency.

Per capita income variables were positive affects efficiency. When there was an increase in $1 \%$ in per capita income, the school efficiency increased by 0.1317 units. Afonso \& Aubyn (2006) also found that GDP per head and parents' educational attainment are highly and significantly correlated to efficiency. In other words, a higher proportion of disadvantaged students reduce school efficiency. This finding is consistent across studies and appears almost unchallenged (Alexander \& Jaforullah, 2010; Bradley \& Taylor, 2010; Rassouli-currier, 2007). The study's findings also found that the average wage factor is not significant in influencing the technical efficiency of secondary school.

Table 6. Estimation Results of Static Panel Data for School Efficiency Determinants for The Developed and Less Developed States in Malaysia

\begin{tabular}{lcccc}
\hline & \multicolumn{2}{c}{ Developed states } & \multicolumn{2}{c}{ Less developed states } \\
& Fixed effect & Random effect & Fixed effect & Random effect \\
\hline LnSize & -0.0419 & -0.0419 & -0.1093 & -0.0605 \\
& $(-1.87)^{* * *}$ & $(-3.55)^{* * *}$ & $(-4.68)^{* * * *}$ & $(-4.50)^{* * * *}$ \\
LnWage & 0.3935 & 0.3406 & 0.1083 & 0.2471 \\
& $(15.40)^{* * *}$ & $(13.72)^{* * *}$ & $(3.43)^{* * * *}$ & $(8.81)^{* * *}$ \\
LnPercap & 0.2285 & 0.2539 & 0.2634 & 0.0609 \\
& $(10.13)^{* * *}$ & $(11.20)^{* * *}$ & $(6.64)^{* * * *}$ & $(1.98)^{* *}$ \\
No.of & & & & 1414 \\
observation & 1536 & 1536 & 1414 & 293 \\
No. of groups & & & 293 & \\
R-square & 316 & 316 & & 0.2392 \\
& & & 0.2610 & 0.0000 \\
Nilai Prob $>\mathrm{F}$ & 0.4778 & 0.4776 & 0.0000 & \\
Prob $>$ chi2 & 0.0000 & 0.0000 &
\end{tabular}

Note: The figure in parentheses is t value. ${ }^{* *}$ Significant at level $1 \% ;{ }^{* *}$ Significant at level $5 \%$.

Table 6 summarizes the results of estimating secondary school efficiency determinants for the developed and the less developed states in Malaysia. There are 316 secondary schools in the developed states and 293 secondary schools in the less developed states. School size variables were negatively influence efficiency in both developed and less developed states. When there was an increase of $1 \%$ in school size, the total efficiency 
decreased by 0.0419 units in developed states and 0.109 units in less developed states. Increasing school size will reduce school efficiency. Average wages and per capita income have a positive impact on school efficiency for both the developed and the less developed states. The increase of $1 \%$ average wages resulted in increased school efficiency by 0.3935 units in developed states and a 0.1083 unit in less developed states. The increased $1 \%$ in per capita income increased school efficiency by 0.228 units in developed states, and 0.263 unit in less developed states. The student socioeconomic status and parental education significantly influence the schools' efficiency, especially in rural areas (Hussain et al. 2015). These findings are inconsistent with Borge \& Naper (2006), indicates that a high level of municipal revenue, a high degree of party fragmentation, and a high share of socialists in the local council are associated with low educational efficiency. The developed states fixed effects model shows a relatively high $\mathrm{R}^{2}$ of 0.4778 , which means a $48 \%$ change in the dependent variables explained by the explanatory variables. Compared to less developed states with a lower $\mathrm{R}^{2}$ of 0.2610 , only a $26 \%$ change in the dependent variable is explained by the explanatory variables.

Table 7. Estimated Results of Fixed Effects and Random Effects of static panel data on the determinants of urban and rural schools in Malaysia

\begin{tabular}{lcccc}
\hline & \multicolumn{2}{c}{ Urban } & \multicolumn{2}{c}{ Rural } \\
& Fixed effect & Random effect & Fixed effect & Random effect \\
\hline LnSize & -0.0208 & -0.0618 & -0.1186 & -0.0671 \\
& $(-1.06)$ & $(-5.32)^{* * *}$ & $(-4.17)^{* * *}$ & $(-4.80)^{* * * *}$ \\
LnWage & 0.2727 & 0.3187 & 0.1734 & 0.3352 \\
& $(11.80)^{* * *}$ & $(13.65)^{* * *}$ & $(4.74)^{* * *}$ & $(10.48)^{* * *}$ \\
LnPercap & 0.2622 & 0.0817 & 0.2621 & 0.2459 \\
& $(11.48)^{* * *}$ & $(4.07)^{* * *}$ & $(6.44)^{* * *}$ & $(6.15)$ \\
No.of observation & 1855 & 1855 & 1095 & 1095 \\
No. of groups & & & & \\
R-square & 384 & 384 & 225 & 225 \\
Nilai Prob > F & 0.4006 & 0.3781 & 0.3046 & 0.2615 \\
Prob > chi2 & 0.0000 & 0.0000 & 0.0000 & 0.0000 \\
\hline
\end{tabular}

Note: The figure in parentheses is t value. ${ }^{* *}$ Significant at level 1\%; ${ }^{*}$ Significant at level 5\%.

Table 7 summarizes the results of estimating secondary school efficiency for urban and rural schools. There are 384 secondary schools in urban areas and 225 secondary schools in rural areas. School size factors for urban areas were not significant in influencing school efficiency. These findings contradict the findings by Kantabutra and Tang (2006), who found that school size has a significant effect and positive relationship with school efficiency in urban areas. However, rural areas show that school size factors negatively and significant at a $1 \%$ significant level in influencing efficiency. The one percent increases in school size followed by a 0.1186 unit decline in school efficiency. However, the monthly average wage and per capita income positively and significant at a $1 \%$ significant level in influencing efficiency in both locations. A $1 \%$ increase in average monthly wages increased school efficiency by 0.2727 units in an urban school and 0.1734 units in a 
rural school. In comparison, the per capita income factors show that a $1 \%$ increase in per capita income increased the rate of 0.262 unit school efficiency in urban and rural schools. Hussain et al. (2015) found that parents' socioeconomic factors influence the efficiency of rural schools. The fixed-effect model in urban school shows $\mathrm{R}^{2}$ of 0.4006 . This means that the explanatory variable explains a $40.1 \%$ change in the dependent variable. In rural areas, $\mathrm{R}^{2}$ is 0.3046 , this means that only $30.5 \%$ of the changes in the dependent variable.

\section{Conclusion}

The study's focal point is to examine the level and determinants of technical efficiency of selected secondary schools in Malaysia. The efficiency score for each school has constructed using a DEA method, whereas the static panel data technique has been used to model the determinants of school technical efficiency. The main findings revealed that secondary school's technical efficiency is still moderate, although $88 \%$ of the operating secondary school's technical efficiency was above 0.50 by the year 2014 . Each category's technical efficiency is as follows, urban schools $86.7 \%$, rural schools $91.2 \%$, developed states $89.2 \%$, and $87.4 \%$ in less developed states. The regression result reveals that school size is significant and negatively affects school efficiency in rural areas.

Meanwhile, per capita income and average wages have a positive relationship since the result shows it increases the school's efficiency in urban and rural areas. Schools in the developed and less developed states show that the school size factor negatively affects, whereas the monthly average wage and per capita income are positively related to efficiency. The school size factor was not significant for urban schools, while school size harms rural schools' efficiency. Average wages and per capita income have a positive effect both on urban and rural schools' efficiency.

Results reveal some important implications for policymakers and secondary school management in Malaysia. First, the study's significant results have shown a meaningful and negative relationship between school size and school efficiency. This result explains that an increase in the school's size will lower the school's efficiency. Therefore, determining the number of pupils in a class is crucial to ensure increased efficiency. The new schools and the upgrading of existing schools are necessary to ensure that all facilities are fully utilized and thus improve the school's efficiency. The significant and positive relationship between average wages and per capita income and school efficiency suggests that school efficiency can be improved if the government considers increasing average wages and existing per capita income. This effort can help parents get better opportunities to help schools improve learning facilities both at school and home. Besides, the Federal and State governments should allocate their funding differently to narrow the socioeconomic differences between low-income families and high-income families. So, the importance of family economic background to students' educational success would decline, making academic achievement depend on ability and effort. The school administration and management should also consider the best way to develop school excellence with more authority given by the Ministry of Education. 
The study, however, has a limitation. It is difficult to have access to secondary school data. Most of the data are confidential, primarily Sijil Pelajaran Malaysia result. This condition has caused difficulties in obtaining extensive school data, which is valuable for this study. Based on the limitation that has been encountered in this study, the following are some recommendations for further research. First, increasing the number of existing schools to obtain the results of more comprehensive technical efficiency. Second, further research to identify and compare the results of using two different approaches in modeling the DEA and SFA (Stochastic Frontier Analysis). The comparisons of the results can indicate whether there are differences or similarities in the obtained results.

\section{References}

Afonso, A., \& Aubyn, M. S. (2006). Cross-country Efficiency of Secondary Education Provision: A Semi-parametric Analysis with Non-discretionary Inputs. Economic Modelling, 23(3), 476-491. https://doi.org/10.1016/j.econmod.2006.02.003.

Agasisti, T. (2014). The Efficiency of Public Spending on Education: An Empirical Comparison of EU Countries. European Journal of Education, 49(4), 543-557.

Agasisti, T., Bonomi, F., \& Sibiano, P. (2014). Measuring The "Managerial" Efficiency of Public Schools: a Case Study in Italy. International Journal of Educational Management, 28(2), 120-140.

Agasisti, T. \& Zoido, P. (2015). The Efficiency of Secondary Schools in an International Perspective Preliminary results from PISA 2012. OECD Education Working Papers, No. 117.

Akbar, R. (2018). Evaluating The Efficiency Of Indonesia's Secondary School Education. Jurnal Pendidikan Indonesia, 7(1), 1-9.

Alexander, W. R. J., Haug, A. A., \& Jaforullah, M. (2010). A Two-stage Double-Bootstrap Data Envelopment Analysis of Efficiency Differences of New Zealand Secondary Schools. Journal of Productivity Analysis, 34(2), 99-110.

Atici, K. B. \& Podinovski, V. V. (2015). Using Data Envelopment Analysis for The Assessment of Technical Efficiency of Units with Different Specialisations: An Application to Agriculture. Omega, 54, 72-83.

Arshad, M. N. M. (2013). How Efficient is Malaysia's Secondary Education? Jurnal Pendidikan Malaysia, 38(1), 25-40.

Badri, M., Mohaidat, J., \& El Mourad, T. (2014). Measuring the Efficiency of Public Schools using Data Envelopment Analysis-An Exploratory Study. Journal of Education and Practice, 5(37), 215-232.

Borge, L. E., \& Naper, L. R. (2006). Efficiency Potential and Efficiency Variation in Norwegian Lower Secondary Schools. FinanzArchiv/Public Finance Analysis, 62(2), 221-249.

Bradley, S., Johnes, J., \& Little, A. (2010). Measurement and Determinants of Efficiency and Productivity in The Further Education Sector in England. Bulletin of Economic Research, 62(1), 1-30. https://doi.org/10.1111/j.1467-8586-2009.00309.x. 
Buerger, C., \& Bifulco, R. (2019). The Effect of Charter Schools on Districts' Student Composition, Costs, and Efficiency: The Case of New York State. Economics of Education Review, 69, 61-72.

Calero, J., Murillo Huertas, I. P., \& Raymond, J. L. (2020). Efficiency in The Transformation of Schooling into Competences: A Cross-country Analysis Using PIAAC Data. Bulletin of Economic Research. https://doi.org/10.1111/boer.12249.

Coelli, T. J., Rao, D. S. P., O’Donnell, C. J., \& Battese, G. E. (2005). Introduction to Efficiency and Productivity Analysis. Berlin: Springer Science \& Business Media.

Danu, A. \& Zuhdi, U. (2013). The Government Expenditure Efficiency towards the Human Development. Procedia Economics and Finance, 5, 615-622.

Denaux, Z. S. (2009). Determinants of Technical Efficiency: Urban and Rural Public Schools in The State of Georgia. Southwestern Economic Review, 36, 105-115.

Drebee, H. A., \& Razak, N. A. A. (2018). Measuring the Efficiency of Colleges at the University of Al-Qadisiyah-Iraq: A Data Envelopment Analysis Approach. Jurnal Ekonomi Malaysia, 52(3), 163-179.

Farrell, M. J. (1957). The Measurement of Productive Efficiency. Journal of the Royal Statistical Society, 120(3), 253-290.

Goncharuk, A. G. (2018). Efficiency vs Effectiveness: Alternative Metrics for Research Performance. Journal of Applied Management and Investments, 7(1), 24-37.

Haelermans, C. \& Ruggiero, J. (2017). Non-Parametric Estimation of The Cost of Adequacy in Education: The Case of Dutch Schools. Journal of the Operational Research Society, 68(4), 390-398.

Hausman, J. (1978). Specification Tests in Econometrics. Econometrica, 46(6), 1251-1271.

Huguenin, J. M. (2015). Determinants of School Efficiency: The Case of Primary Schools in The State of Geneva, Switzerland. International Journal of Educational Management, 29(5), 539-562.

Hussain, Z., Mehmood, B., Siddique, M. A. \& Afzal, S. (2015). Determination the Technical Efficiency of Public Schools in Pakistan. Science International, 27(4), 3605-3612.

Johnes, G., \& Virmani, S. (2020). The Efficiency of Private and Public Schools in Urban and Rural Areas: Moving Beyond The Development Goals. International Transactions in Operational Research, 27(4), 1869-1885.

Johnson, A. L. \& Ruggiero, J. (2014). Nonparametric Measurement of Productivity and Efficiency in Education. Annals of Operations Research, 221(1), 197-210.

Kantabutra, S., \& Tang, J. C. (2006). Urban-Rural and Size Effects on School Efficiency: The Case of Northern Thailand. Leadership and Policy in Schools, 5(4), 355-377.

Kantabutra, S. (2009). Using a DEA Management Tool through a Nonparametric Approach: An Examination of Urban-Rural Effects on Thai School Efficiency. International Journal of Education Policy and Leadership, 4(2), 1-14. 
Liang, Y. H. Z. Z. W. (2014). Efficiency of Primary Schools in Beijing, China: an Evaluation by Data Envelopment Analysis. International Journal of Educational Management, 23(1), 34-50.

Muvawala, J. \& Hisali, E. (2012). Technical efficiency in Uganda's Primary Education System: Panel Data Evidence. African Statistical Journal Journal, 15, 21-30.

Nahar, M. \& Arshad, M. (2014). Efficiency of Secondary Education in Selected OIC Countries. Global Education Review, 1, 53-75.

Nauzeer, S., Jaunky, V. C., \& Ramesh, V. (2018). Efficiency Assessment of Secondary Schools in Mauritius: A DEA Approach. International Journal of Environmental and Science Education, 13(10), 865-880.

Podinovski, V. V., Ismail, I., Bouzdine-Chameeva, T. \& Zhang, W. (2014). Combining the Assumptions of Variable and Constant Returns to Scale in The Efficiency Evaluation of Secondary Schools. European Journal of Operational Research, 239(2), 504-513.

Porcelli, F. (2009). Measurement of Technical Efficiency . A Brief Survey on Parametric and Non-Parametric Techniques. Working Paper University of Warwick, 1-27.

Psacharopoulos, G. \& Patrinos, H. A. (2004). Returns to Investment in Education: A Further Update. Education Economics, 12(2), 111-134.

Psacharopoulos, G. \& Patrinos, H. A. (2018). Returns to Investment in Education: a Decennial Review of The Global Literature. Education Economics, 26(5), 445-458.

Rassouli-Currier, S. (2007). Assessing The Efficiency of Oklahoma Public Schools: a Data Envelopment Analysis. Southwestern Economic Review, 34, 131-144.

Scippacercola, S. \& Ambra, L. D. (2014). Estimating the Relative Efficiency of Secondary Schools by Stochastic Frontier Analysis. Procedia Economics and Finance, 17(14), 79-88.

Tsakiridou, H., \& Stergiou, K. (2013). Evaluating the Efficiency of Primary School Education. Proceeding $2^{\text {nd }}$ International Conference on Advanced Research, 279-286.

Yahia, F. B., \& Essid, H. (2019). Determinants of Tunisian Schools' Efficiency: A DEATobit Approach. Journal of Applied Management and Investments, 8(1), 44-56.

Baltagi, B. H. (2008). Econometric Analysis of Panel Data. New Jersey: John Wiley \& Sons. 